\title{
Evaluation of Treatment of Ear Lobe Keloid with Triamcinolone Injection and Surgical Excision
}

\author{
Authors

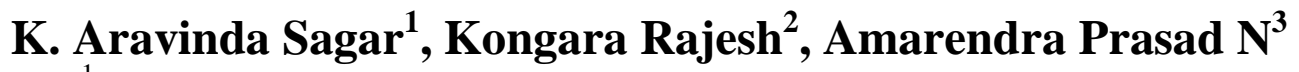 \\ ${ }^{1}$ MNR Medical College and Hospital, Sangareddy, Telangana, India \\ Email:aru044@gmail.com \\ ${ }^{2}$ MNR Medical College and Hospital, Sangareddy, Telangana, India \\ Email: Rajeshkongaral@gmail.com \\ ${ }^{3}$ MNR Medical College and Hospital,Sangareddy, Telangana, India \\ Email: amarendra_1999@yahoo.com
}

\begin{abstract}
The study includes 42 consecutive patients with 68 ear lobe keloids. Patients underwent local infiltration of triamcinolone acetonide (TCN) at concentrations of 40mg/ml (Group 1) and $20 \mathrm{mg} / \mathrm{ml}$ (Group 2). Different volume of TCN infiltrate according to the size of the lesion. Treatment consisted of three monthly injections before surgery, excision of keloid in the fourth month and perioperative infiltration, followed by two more infiltration of TCN within two months. Post-treatment follow-up of patients was done forl2 months. RESULTS: TCN at concentrations of $20 \mathrm{mg} / \mathrm{ml}$ and $40 \mathrm{mg} / \mathrm{ml}$ were effective for the treatment of keloids along with surgical excision, no difference between the groups $(p=0.73)$.

CONCLUSION: The combination of infiltration of TCN monthly (1.2mg to 2.0mg per $\mathrm{mm}^{\underline{3}}$ ) and surgical excision is effective for treatment of ear lobe keloid.
\end{abstract}

KEY WORDS: Keloid; Triamcinolone Acetonide; Wound Healing; Surgical excision; Recurrence.

\section{INTRODUCTION}

The wound repair process covers a wide spectrum of results, from the complete absence of healing to exuberant scarring. The mechanism of regulation of abnormal healing is not known. The process that keeps the scar on proliferative and inflammatory phase is not known. Keloids are scars that respond in an exaggerated way to a skin lesion. Keloid rise above the skin level, extend beyond the border of the original wound and rarely regress spontaneously ${ }^{1}$. Keloids tend to occur 3 months to year after initial insult, and even minor injuries can result in large lesions ${ }^{1}$. Certain body sites have a higher incidence of keloid formation, including the skin of the earlobe as well as the deltoid, presternal and upper back regions ${ }^{1}$.

A keloid scar is defined as excessive scar tissue extends beyond the boundaries of the original incision or wound .Its etiology is unknown, but it is associated with elevated levels of growth factor, deeply pigmented skin, an inherited tendency and certain areas of the body ${ }^{2}$.The keloid scar shows excess collagen (more type III) with hypervascularity $^{2}$. Keloids are 15 times more 
common in darker -pigmented ethinicities ${ }^{1}$. Men and women are equally affected ${ }^{1}$.

Genetically, the predilection to keloid formation appears to be autosomal dominant with incomplete penetration and variable expression ${ }^{1}$. Its incidence is higher in between ten and 30 years of age ${ }^{3}$, with no preference between genders. Keloids are multifactorial, relating with physical, chemical, biological and endogenous agents. Keloid fibroblast have enhanced expression of TGF- $\beta 1$.TGF- $\beta 2$, VEGF, and plasminogen activator inhibitor-1 and an increase number of PDGF receptors: they also have upregulated antiapoptotic gene expression, which can be differentially expressed within different areas of the same scar. Fibroblasts derived from keloids have an increased expression of the p $63^{4}$ gene, with increased response to the organic stimuli involved in wound healing. The beta transforming growth factor (TGF $\beta 1$ ) is also high in keloids 5 .

Treatment goals include restoration of function to the area, relief of symptoms, and prevention of recurrence. Many patients seek intervention due to cosmetic concerns. Corticosteroid therapy is considered the best treatment for keloids ${ }^{3.6}$. Triamcinolone (TCN) in keloids has been used since 1965 due to its efficacy ${ }^{7}$. Intralesional corticosteroid injections decrease fibroblast proliferation, collagen and glycosaminoglycan synthesis, the inflammatory process, and TGF- $\beta$ levels.

The mechanism of action of intradermal TCN on the injury is not fully known. Its greatest effect is in the inflammatory and proliferative phase, interfering in local edema and erythema. There is evidence of its effect on the phagocytic activity of macrophages and modulation of the fibroblasts function in collagen synthesis.

The therapeutic objective depends on the patient's symptoms and aesthetic complaints caused by the keloid. Even after thorough search of the literature, there is still no effectiveness-established treatment for keloid cure. This study presents the evaluation of the combined approach consisted of application of $\mathrm{TCN}$ and surgical resection to treat earlobe keloids.

\section{AIMS AND OBJECTIVIES}

1. To evaluate the efficacy of application of $\mathrm{TCN}$ and surgical resection to treat earlobe keloids.

2. To evaluate the dose of TCN required for treatment of different sized keloids.

\section{METERIAL AND METHODS}

All keloids were caused by piercing injury for earring placement.

Patients with skin infections and those with age under 18 years were excluded.

To determine the optimal dose of TCN in the treatment of keloids, the patients were divided into two groups to receive different drug concentrations: The patients are divided into two groups depending upon the size of the keloids, Group $1(40 \mathrm{mg} / \mathrm{ml})$, Group $2(20 \mathrm{mg} / \mathrm{ml})$. The amount of TCN injected into the base of the lesion is proportional to the volume of the keloid. We injected $0.05 \mathrm{ml}$ to $0.1 \mathrm{ml}$ TCN per $\mathrm{mm}^{3}$ of keloid monthly for three months. The volume of keloids (V) is calculated in the preoperative phase in cubic millimeters $\left(\mathrm{mm}^{2}\right)$. In the fourth month, the patients underwent excision of the keloid followed by TCN injection into the open area of the wound edges, using the same volume injected earlier. The wound was sutured with monofilament 4-0 nylon. All procedures were performed under local anesthesia with $1 \%$ lidocaine injected into the keloid.

To verify the effectiveness of the treatment, patients were followed for at least one year after the last dose of corticosteroids. To assess the appropriate dose of TCN to be injected, we considered as therapeutic success, when there is no recurrence of the injury after surgical removal and infiltration of corticosteroids. We compared the number of relapses in two groups. We considered relapse when there was scar growth beyond the limits of the wound at the end of treatment, combined with complaints of itching and pain. Two variables were 
considered together, as each indicates failure in the treatment of keloids.

\section{RESULTS}

Group $1(40 \mathrm{mg} / \mathrm{ml})$, consisting of 24 patients with 38 keloids; Group $2(20 \mathrm{mg} / \mathrm{mL})$, consisting of 18 patients with 30 keloids (table 1 ).

In Group 1 (TCN upto $40 \mathrm{mg} / \mathrm{ml}$ ) two of the 24 patients $(8.3 \%)$ experienced an anaphylactic reaction after the second infiltration. There was general malaise, lip swelling, flushing, dry cough, abdominal pain, symptoms that improved after intravenous administration of 1litre of physiological saline. There were two keloid recurrences in less than one year $(8.3 \%)$ (Table :2).

In Group 2 (TCN $20 \mathrm{mg} / \mathrm{ml}$ ), one of the 18 patient $(5.5 \%)$ had anaphylactic reactions to TCN after the second infiltration. There was wound infection in one patient, treated with cephalexin for ten days without modification of the therapeutic result, considered optimal. There was one recurrence of keloid in less than one year $(5.5 \%)$. There was no difference in the evolution of the symptoms and scar appearance between the groups that received $20 \mathrm{mg} / \mathrm{ml}$ and $40 \mathrm{mg} / \mathrm{ml}$. After the third infiltration, all patients were asymptomatic and their injuries did not progress. There was improvement in scar stiffness and size regression. There was no difference $(p=0.73)$ between the results obtained with patients undergoing infiltration of $40 \mathrm{mg} / \mathrm{ml}$ and $20 \mathrm{mg} / \mathrm{ml}$ TCN.

Table: 1 Age distribution and number distribution of the patients

\begin{tabular}{|l|l|l|l|}
\hline $\begin{array}{l}\text { Age } \\
\text { (years) }\end{array}$ & $\begin{array}{l}\text { Total } \\
\text { No. of } \\
\text { patients }\end{array}$ & $\begin{array}{l}\text { Number of } \\
\text { patients } \\
\text { with Single } \\
\text { keloid }\end{array}$ & $\begin{array}{l}\text { Number of } \\
\text { patients with } \\
\text { Multiple } \\
\text { keloids (2 } \leq \text { ) }\end{array}$ \\
\hline $\begin{array}{l}<18- \\
20\end{array}$ & 7 & 5 & 2 \\
\hline $21-30$ & 23 & 9 & $14 *$ \\
\hline $31-40$ & 8 & 2 & 6 \\
\hline $41<$ & 4 & 2 & 2 \\
\hline 2 patients in this group have 3 keloids.
\end{tabular}
beta therapy is the most frequently used ionizing radiation mode ${ }^{10}$. However, it is known for its radiation mode . However, it is known for its
carcinogenic potential, contraindication in children,

Table : 2 Complications after surgical excision of keloids

\begin{tabular}{|l|l|l|l|}
\hline Group & $\begin{array}{l}\text { No. of } \\
\text { patients }\end{array}$ & $\begin{array}{l}\text { Wound } \\
\text { infection }\end{array}$ & $\begin{array}{l}\text { Recurr } \\
\text { ence }\end{array}$ \\
\hline $\begin{array}{l}1 \text { (TCN upto } \\
40 \mathrm{mg} / \mathrm{dl})\end{array}$ & 24 & 0 & 2 \\
\hline $\begin{array}{l}20 \mathrm{TCN} \\
20 \mathrm{mg} / \mathrm{dl})\end{array}$ & 18 & 1 & 1 \\
\hline
\end{tabular}

There was no difference between the results obtained with patients undergoing infiltration of $20 \mathrm{mg} / \mathrm{ml}$ and $40 \mathrm{mg} / \mathrm{ml}$ TCN. Even a thorough review of the literature does not allow precise analysis of the results proclaimed. Some causes of this difficulty are: lack of homogeneity description and characterization of anomalous scars; limited number of patients; statistical methodology used; insufficient follow-up; and different criteria used to define relapse.

\section{DISCUSSION}

Treatment of keloids is based on potential medical intervention, and they act in the complex cascade of events leading to wound healing: manipulation of the intrinsic properties of wound synthesis process; correction of the balance between normal physiological and abnormal collagen synthesis, modification of various immune and inflammatory responses that occur during the healing process. compression of the keloid, cryosurgery application of silicone plates, intralesional injection of corticosteroids, operative excision followed or not by radiotherapy, isolated radiotherapy and laser application.

Cryotherapy lends itself to treat minor injuries in leucodermas, by leading to keloid cold ischemia and possible volumetric reduction of the lesion ${ }^{8}$. Radiotherapy is used usually after surgical excision. The keloid is the benign lesion most often treated by radiotherapy ${ }^{9}$, which was first used in 1906 . The
Therapeutic options include, in most cases: 
and it's side effects on scars and keloids, such as atrophy, hypopigmentation, and skin necrosis.

The LASER (Light Amplification by Stimulated Emission of Radiation), has shown good results in the treatment of keloids. It acts by modulating the anomalous tissue growth, but the results depend on the type of laser, exposure time and location of the keloid $^{11}$. The isolated surgical removal entails risk of recurrence, ranging from $45 \%$ to $100 \%$ of the cases, and should never be used in monotherapy ${ }^{12}$.

Among the intralesional corticosteroids, the preferred drug is triamcinolone (TCN). Although there are studies on general aspects and treatment of keloids, the best concentration and TCN dose for treatment has not yet been determined.

The concentrations proposals in the literature range from $10 \mathrm{mg} / \mathrm{ml}$ to $40 \mathrm{mg} / \mathrm{ml}$ and the total dose, up to $120 \mathrm{mg}^{13}$. TCN is the only drug approved for keloid treatment by the Food and Drug Administration (FDA), USA. It's topical use, however, is ineffective to treat keloids. In this study, the total dose infiltrated in keloids was lower than that found in the literature, and yet, therapeutic success was obtained in almost all patients.

Anaphylactic reactions using TCN are well documented. Corticosteroids are paradoxically responsible for anaphylactic type 1 reactions, mediated by IgE antibodies. The allergens may be the steroids themselves or the liquid used in the solution, usually carboxymethylcellulose ${ }^{14}$ and succinate $^{15}$. The infiltration of TCN at the base of keloid is intended to act in the place of the mediators of the healing process and of the fibroblasts with greater replicative capacity. The retention of the drug in small volumes in the scar site reduces its systemic effects.

The development of stem cell research ${ }^{15}$ has helped to elucidate the balance of formation and cellular remodeling activity. It is described that flags (cytokines), molecular alterations in receptor cytoplasmic membrane of fibroblasts and genetic mutations alter the healing process ${ }^{16}$. Growth factors are important in the modulation of various cellular activities ${ }^{17}$. New therapeutic strategies to enhance wound healing and promote the formation of healthy scars are currently being studied, using anti-TGF-â antibodies. The administration of lower doses of corticosteroids is insufficient, and higher doses are unnecessary to obtain good therapeutic results.

\section{References}

1. F. Charles Brunicardi,Dans K. Anderson, Timothy R. Billar,David L.Dunn, John G. Hunter, Jeffrey B.Mathews, Raphael E. Pollock: Schwartz's principles of surgery: tenth edition:ch.9,wound healing, pg 261-64.

2. M. Townsend,Jr., R.Daniel Beauchamp, B.Mark Evers, Kenneth L. Mattox: Sabiston Textbook of surgery: The Biological Basis of Modern Surgical Practice, 19 ${ }^{\text {th }}$ edition, ch.7,wound healing, pg 164-66.

3. Urioste SS, Arndt KA, Dover JS. Keloidalscars and hypertrophic scars: review and treatment strategies. SeminCutan Med Surg.1999;18(2):159-71.

4. De Felice B, Ciarmiello LF, Mondola P, Damiano S, Seru R, Argenziano C, et al. Differential p63 and p53 expression in human keloid fibroblast and hypertrophic scar fibroblasts. DNA Cell Biol.2007;26(8):541-7.

5. Bettinger DA, Yager DR, Diegelmann RF, Cohen IK. The effect of TGF-beta on keloid fibroblast proliferation and collagen synthesis. PlastReconstr Surg. 1996;98 (5):827-33.

6. Ketchum LD, Robinson DW, Masters FW. Follow-up on treatment of hypertrophic scars and keloids with triamcinolone. PlastReconstr Surg.1971;48(3):256-9.

7. Babin RW, Ceilley RI. The freeze-injection method of hypertrophic scar and keloid reduction. Otolaryngol Head Neck Surg. 1979;87(6):911-4..

8. Shepherd JP, DawberRP.The response of keloid scars to cryosurgery.Plastic Reconstr Surg.1982;70(6):677-82. 
9. Botwood N, Lewanski C, LowdellC. The risks of treating keloids with radiotherapy. $\mathrm{Br}$ J Radiol.1990;72(864):1222-4.

10. DarziMA,Chowdri NA, Kaul SK, Khan M. Evolution of various methods of treating keloids and hypertrophic scars: a 10-year follow-up study. $\mathrm{Br} \quad \mathrm{J}$ Plast Surg. 1992;45(5):374-9.

11. Abergel RP, Meeker CA, Oikarinen H, Oikarinen AI, Uitto J. Retinoid modulation of connective tissue metabolism in keloid fibroblast cultures. Arch Dermatol. 1985; 121(5):632-5.

12. Shaffer JJ, TaylorSC, Cook-Bolden F. Keloidal scars: a review with a critical look at therapeutic options. J Am Acad Dermatol.2002;46(2 Suppl Understanding): S63-97.

13. Griffith BH, Monroe CW, McKinney P.A follow-up study on the treatment of keloids with triamcinolone acetonide. Plast Reconstr Surg. 1970;46(2):145-50.

14. Patterson DL, Yunginger JW, Dunn WF, Jones RT, Hunt LW. Anaphylaxis induced by carboxymethylcellulose component of injectable triamcinolone. Ann Allergy Asthma Immunol.1995;74(2):163-6.

15. TuanTL, NichterLS.The molecular basis of keloid an hypertrophic scar formation. Mol Med Today.1998;4(1):19-24.

16. Kim WJ. Cellular signaling in tissue regeneration. Yonsei Med J. 2000;41 (6):692-703.

17. Lee TY, Chin GS, Kim WJ, Chau D, Gittes GK, Longaker MT. Expression of transforming growth factor beta 1, 2, and 3 proteins in keloids. Ann Plast Surg. 1999;43(2):179-84. 